\title{
An Evaluation of the Approaches Used by Graduates in Job Search, Ghana
}

\author{
Prince Adjei, Jamal Mohammed* \\ Department of Liberal Studies, Koforidua Polytechnic, Koforidua, Eastern Region \\ *Corresponding author: nakohinaa@gmail.com
}

Received February 14, 2014; Revised February 23, 2014; Accepted March 03, 2014

\begin{abstract}
The study, evaluation of the approaches used by graduates in job search in Ghana, employed an exploratory design approach by surveying both employed and unemployed graduates using a questionnaire. A total of 132 employed graduates and 128 unemployed graduates were reached for the study.The findings of the study revealed that both the employed and unemployed graduates consider use of application letters, personal contacts, references and networking to be an effective means in gaining job employment. Majority of the respondents indicated that, the response rate of companies to the use of the above mentioned methods of job search was very high and encouraging. Majority of the respondents indicated that they received responses from about five companies offering them a chance of dialogue about the possibility of handing them employment. Most of the employed graduates expressed their desire to recommend it and also to re-use them should the need to change job arise. The extent of their belief in the use of these methods of job search is that using them in job search can guarantee a favourable outcome of finding a job within one year.The study recommends among others that organisations should ease the requirements used as criteria for qualification for employment so that more graduates can be offered work. Also, it is suggested that graduates should be more confident and persistent in their job search, exploring more other job search options to secure themselves work. In addition, the researchers advise that HR experts and managers should build their recruitment and selection strategies around advert and the use of websites and social media.
\end{abstract}

Keywords: evaluation, approaches, graduates, job Search, Ghana

Cite This Article: Prince Adjei, and Jamal Mohammed, "An Evaluation of the Approaches Used by Graduates in Job Search, Ghana." Journal of Finance and Economics, vol. 2, no. 1 (2014): 36-43. doi: $10.12691 / \mathrm{jfe}-2-1-5$.

\section{Introduction}

The search for employment is tedious, stressful and time consuming. Graduates especially seek to gain employment soon after school or graduation. They use different approaches and methods to gain employment. Studies have shown that graduates in Europe resort to the use of adverts and networks. But in Ghana it has not vividly established which methods are used by graduates to seek employment and the effectiveness in gaining and securing jobs. This study therefore seeks to establish the methods and approaches used by graduates in Ghana to gain employment and their effectiveness.

Because of the challenges in job search, many approaches are used by graduate and the unemployed in the course of seeking for jobs. Job Search has proved to be stressful at times for graduate and the unemployed. Many graduates are stressed up when seeking jobs as a result of the many challenges that they go through. The stress is further aggravated if the person is over 45 or 50years and was laid off from the job that they thought they were going to retire from (Wanberg et al, [25]).

Some of the most effective job search techniques have nothing to do with actually searching for and applying for job openings. Instead, the best job search techniques involve the students positioning themselves to job hunt and tapping into the resources that can boost and expedite job hunt.

\subsection{Objectives of the Study}

The broad objective of this study is to evaluate the approaches used by graduates in job search in Ghana.

The specific objectives were to:

- Assess the various approaches used by graduates in job search.

- Examine the effectiveness of the approaches in job search.

- Determine the challenges that graduates encounter in searching for jobs.

- Make recommendations as to how the identified challenges can be resolved.

Based on the objective of the study, the following research questions were posed for examination:

- Which approaches are used by graduates in job search?

- How effective are the approaches used in job search?

- What challenges do graduates encounter in job search?

Results and suggestions from this study can be used by the business executives, entrepreneurs, government 
agencies and policy makers to design effective recruitment and selection strategies to attract the best talent into the organization. It would again serve as a source of reference for other researchers to research further into the subject matter.

The study is limited to the study of graduates from Central University College, Methodist University College, University of Ghana and Regent University College as well as some selected organisations in Ghana.

\section{Literature Review}

In the view of Kingston [12], labour-market entrants are able to choose within a wide range of job search methods. They may send direct applications to employers, search through the employment services, or utilise more informal search methods as relatives and friends. One approach used is the direct approach. Sometimes called the "speculative approach"; this involves proactively contacting organizations to offer one's services.

Adding to the methods of job search, Thompson et. al., [23] noted that, one of the other methods that graduates also adopt is networking. It is said that, the majority of job vacancies are never advertised, often referred to as the "hidden job market." Another method suggested by Fin and Morgan [4] is the use of referrals. This comes from individuals you know, however, this method may get you an invitation to apply for a position without actually searching for a new a job.

Also Seam [20] indicates that job fairs are also used as means of search for jobs. Job fairs are typically targeted toward specific industries, though some job or recruitment fairs are more generalized.

Blau and Robins [1] indicated that it is difficult to get a full picture of the range of jobs graduates enter from the statistics alone, but it is far wider than it would have been twenty years ago. Jobs now range from highly paid management training positions aimed exclusively at new graduates, to roles that would not once have been considered 'graduate jobs' at all.

Vilorio [24] asserted that many job seekers research the employers to which they are applying, and some employers see evidence of this as a positive sign of enthusiasm for the position or the company, or as a mark of thoroughness. Information collected might include open positions, full name, locations, web site, business description, year established, revenues, number of employees, stock price if public, name of chief executive officer, major products or services, major competitors, and strengths and weaknesses.

According to Teichler [22] although some graduates are fixed up with an offer of employment long before graduating, many people put off thinking about what to do next until after their exams. Teichler [22] continued that although graduate unemployment is high in most developing countries; significant numbers of graduates too find that they are often underemployed.Teichler [22] defined underemployment as employment that is not making full use of their high-level skills and potential. If a graduate find him/herself in this situation, it is important to realise that he/she is not alone and that many other graduates have worked their way out of it. In some industries it is normal for graduates to start in a very basic role and work their way up (Teichler, 2000). Teichler [22] acknowledge that many graduates find the transition into work harder than they expected. Although it may seem challenging, it is a process most graduates are likely to go through several times in a working life. A positive way to view it is as practice for the future. Throughout a career a graduate will want to review his/her situation and decide if the time is right for a move.

Holzer [11] admitted that it is sometimes difficult to move on from a stopgap job, so graduates must remember the importance of maintaining the job hunt and a positive attitude. Holzer suggested graduates must constantly:

- update and improve their applications;

- review the graduate job market;

- find out what employers want;

- search company profiles;

- polish up interview techniques;

- research types of work;

- keep positive.

Osberg [14] revealed that applications to large employers are usually on an employer application form but could be by CV or standard application form, all of which should be accompanied by a covering letter. Spokane and Hawks [21] indicated that whilst some large employers concentrate their recruitment on an annual cycle of activity, others recruit when they need to fill a post. Smaller employers in particular will almost certainly only recruit when it is necessary to replace someone, or for a new position.

Job searching is the act of looking for employment, due to unemployment or discontent with a current position. The immediate goal of job seeking is usually to obtain a job interview with an employer which may lead to getting hired. The job hunter or seeker typically first looks for job vacancies or employment opportunities (Vilorio, [24]).

Hinshaw [9] stipulated some approaches in job searching. These included;

2.3.1 Networking

\subsubsection{Applying}

2.3.3 Interviewing

According to Kingston [12], the advantages of interviewing include the fact that they are useful to obtain detailed information about personal feelings, perceptions and opinions. Interviewing also allow for more detailed questions to be asked, and provide for ambiguities to be clarified to incomplete answers. The main disadvantages of interviews are that they can be very time-consuming: setting up, interviewing, transcribing, analyzing and feedback.

Godbrah, [5] noted that, online job search resources, including job search sites, job search engines, networking sites, online job search tools, and tips to ensure that you are using all the Internet job search resources available to help find a job online. Some of the advantages of job search on the net include: One of the major advantages of job hunting on the Internet is convenience. From the comfort of once home, one can access thousands of job openings. One need not drive to employers' offices to ask whether they have job openings (Huge, [10]). Wielgosz and Carpenter [26] indicated that three important factors for a successful job search are an awareness of your goals and skills, an understanding of the labor market, and a well-planned job search campaign. 
Using the Montgomery model, it can be explained that though friends and relatives will be a successful method of job search, it does not suggest that this method will increase the chances of finding an acceptable job for all the unemployed. In fact, the model relies on the fact that the unemployed are not homogenous in two respects. Firstly, for imperfect information to be an issue, potential workers must have different productivity levels when they are matched to a given job. Secondly, some are connected to more useful social networks than others.

McGregor [13] considers the possibility that the jobinformation network provided by friends and relatives is local in nature. This would imply that the probability that friends and relatives constitute an effective job-search method would be highly dependent on local neighbourhood characteristics. In particular, he argues that information about jobs is more likely to come from employed people and consequently there will be less useful job information in high unemployment neighbourhoods. The expected probability of obtaining a job offer using information from friends and relatives in high unemployment areas is also likely to be lower as there will be more competition for any available jobs.

Schmitt and Wadsworth [19] find that the most important determinant of job-search method choice is the unemployed person's previous occupational status using a sample of unemployed male benefit recipients in Great Britain.

This section describes the model of Pissarides [16]. It is an important feature that an employment agency is present in the model, although it is not always an intermediary between firms and searchers. Job searchers may choose to register at an employment agency and thus receive offers from the mediator. "Random search" is also available to them, which means directly visiting firms and making inquiries about available vacancies. It is assumed that the unemployed always register (at the employment agency) to be entitled for the unemployment compensation. Nevertheless, some part of these jobless workers may choose the "random search" to increase their employment chances. It is necessary, however, to introduce the cost of random search into the model, because otherwise all unemployed workers would be involved in a random search. The principle idea is that agents choose the optimal mixture of search methods to maximize the value of search. In the same fashion, the firms in the model can also optimize their behaviour with two alternatives possible: advertising the vacancies through the employment agency or privately. As Pissarides puts it:”...firms may change the intensity of their search by switching to methods with higher job-matching probability (which in general be more expensive). It is this variable intensity of search that plays the crucial role in the determination of aggregate behaviour in this model."(Pissarides [16], p.819).

Following the model of Hall [7], a distinctive aspect of Hall (1979) model is that,it stresses the notion of the unemployment and employment duration as an important factor which determines the equilibrium unemployment rate. Hall introduces the concept of an "efficient duration" of employment. For an employer the efficient duration depends on the cost of recruiting and training; and for the worker it depends on the cost of finding new jobs. In tight markets where jobs are easy to find, workers prefer shorter jobs but this imposes higher recruiting cost on employers so they favour longer jobs. Suppose that jobs and workers are perfectly homogeneous. A vacancy in this model is instantly filled, but the unemployed must wait until a job offer arrives, which is a stochastic process. The unemployed accept the first job offer encountered. If they receive more than one, they accept one at random because jobs are homogeneous with respect to wage.

In their model, Burda and Profit [2] consider an individual who can determine his search activity in two dimensions: where to search and how many jobs to apply for. Each spatial unit has a job agency which mediates contacts between searchers and potential employers. Workers apply randomly to firms. Once applied, an individual is invited to an interview after which it is decided whether he is accepted or not. There is a cost, C associated with each interview. If he applies for a job in the region different from the region of origin, say,i, then interview cost is increased to $\mathbf{c}+\mathbf{a} \cdot \mathbf{D}_{\mathbf{i j}}$. Where, $\mathbf{D}_{\mathbf{i j}}$ is the distance between the regionsi and $\mathbf{j}$ in kilometers and $\mathbf{a}$ is thus, a per-kilometer cost of travel. Individuals assume to optimize their search intensity in order to maximize their expected net income. Let $\mathrm{f}$ denote the job finding probability- $r$ the interest rate, and $m$ - the search intensity, which can be thought of as number of jobs to apply for.

It is therefore, very important to undertake a study in evaluating the approaches used by graduates in their job search, since the findings of this study will help future graduates in their job search.

\section{Methodology}

An exploratory research design was adopted in carrying out this study. Since it is not vividly known what methods graduates employ to seek employment. This study sought to explore the methods used by graduates to gain employment in Ghana. According to Haynes [8], a population can be defined as including all people or items with the characteristic one wish to understand. The population of this study involved employed graduates and unemployed graduates who are seeking for employment.

The sample selected for this study are graduates from private and public tertiary institutions and graduates employed in club 100 companies in Ghana. This sample group is selected because they help provide a representative view of graduates approach to employment search in Ghana. A sampling size of 132 employed graduates and 128 unemployed respondents was used in the study. This size was selected due to the belief they will help provide a representative view of graduates approach to employment search in Ghana.

A Purposive sampling technique was employed in selecting employed and unemployed graduate. A purposive sampling was employed because the study needed to focus directly on those individuals involved in the use of the various approaches to job search in Ghana. A questionnaire was employed to collect the data need in relation to the study. The question was structured to explore and establish respondents' knowledge, beliefs and perspectives about the study. The questionnaire was employed because it represented a more convenient way of gathering data from the large sample size. The Data gathered is presented and analyzed using frequency tables. 
It is intended to present the divergent and shared views of respondents on the subject matter understudy.

\subsection{Theoretical Model Specification}

In economic analysis, job search by potential unemployed graduates have theoretical backings in terms of models. This study therefore, provided a theoretical adapted model in support for existing literature. The model is adapted from Richard et al [17].

\subsection{Basic Dynamic Model of Job Search}

Assume that, a worker expect an unemployment vacancy ratio $\mathbf{q}$ and a wage $\mathbf{w}$. The dynamic basic model in the spirit of Pissarides [15] is:

$$
\begin{aligned}
& r U=b+\alpha_{w}(q)[W(w)-U] \\
& r W(w)=w+\lambda[U-W(w)]
\end{aligned}
$$

These could be considered into:

$$
r U=b+\frac{\alpha_{w}(q)(w-r U)}{r+\lambda}
$$

For firms:

$$
\begin{gathered}
r V=-K+\alpha_{e}(q)[J(y-w)-V] \\
r J(y-w)=y-w+\lambda[V-J(y-w)]
\end{gathered}
$$

For free entry it takes:

$$
K=\frac{\alpha_{e}(q)(y-w)}{r+\lambda}
$$

The parameters $\mathrm{w}$ and $\mathrm{q}$ can be maximized at $\mathrm{rV}$, this approximated by free entry to maximize $\alpha_{e}(q)(y-w)$. Eliminating $\mathrm{w}$ using this constraint and again using $\alpha_{e}(q)=q \alpha_{w}(q)$, thus reduces to:

$$
\operatorname{Max} \alpha_{e}(q) \frac{y-r U}{r+\lambda}-q(r U-b)
$$

This could yield the necessary and sufficient first order condition as:

$$
\alpha_{e}^{\prime}(q) \frac{y-r U}{r+\lambda}=r U-b
$$

This is a theoretical model, as eliminating $\mathrm{U}$ and $\mathrm{w}$ from equations (5) and (6) provides an implicit expression for q as:

$$
\frac{r+\lambda+\alpha_{e}^{\prime}(q)}{\alpha_{e}(q)-q \alpha_{e}^{\prime}(q)}=\frac{y-b}{K}
$$

By manipulating the variables $b$ and others in the model would explain the willingness of worker to accept an increase in the unemployment in return for an increase in wage, thereby stimulating firms to increase wages for workers. This theoretical job search model stimulates further empirical expansion on this research paper in future.

\section{Results and Discussions}

Methodist University College, University of Ghana and Regent University College as well as respondents from selected institutions in the Accra Metropolis. 260 questionnaires were retrieved representing $84 \%$ response rate.

Table 1 below shows that $58 \%$ of the respondents were males and the remaining $42 \%$ were females. The implication is that majority of the respondents were males.

Table 1. Gender of Respondents

\begin{tabular}{|c|c|c|}
\hline Gender & Frequency & Percentage (\%) \\
\hline Male & 150 & 58 \\
\hline Female & 110 & 42 \\
\hline Total & $\mathbf{2 6 0}$ & $\mathbf{1 0 0}$ \\
\hline Source: Field Data (2013) & & \\
\hline
\end{tabular}

\subsection{Age}

Concerning the age grouping of the respondents, Table 2 shows that $28 \%$ of the respondents fell between the ages of $18-20$ years, $50 \%$ of the respondents between the ages of $21-30$ years, $19 \%$ of the respondents were also between $31-40$ years and the remaining $3 \%$ of the respondents were 41years and above. The majority of the respondents fall between the ages of 21-30years. This implies that majority of the respondents are matured.

Table 2. Age of Respondents

\begin{tabular}{|c|c|c|}
\hline Age & Frequency & Percentage (\%) \\
\hline $18-20$ & 74 & 28 \\
\hline $21-30$ & 130 & 50 \\
\hline $31-40$ & 48 & 19 \\
\hline 41 and above & 8 & 3 \\
\hline Total & $\mathbf{2 6 0}$ & $\mathbf{1 0 0}$ \\
\hline Source: Field Data (2013) & & \\
\hline
\end{tabular}

In examining whether respondents were able to find their preferred job, Table 3 shows that, $73 \%$ of the employed respondents were able to find their preferred jobs; however, $27 \%$ were not able to find jobs they prefer.

Table 3. Respondents Were Able To Find Preferred Job

\begin{tabular}{|c|c|c|}
\hline Category & Frequency & Percentage (\%) \\
\hline Yes & 96 & 73 \\
\hline No & 36 & 27 \\
\hline Total & 132 & 100 \\
\hline Source: Field Data (2013) & & \\
\hline
\end{tabular}

\subsection{Recommendation of Approach}

With respect to whether employed respondents would recommend the same approaches used to secure their dream jobs to others, it is disclosed in Table 4 that $81 \%$ of the employed graduates would recommend to others the approaches used to secure their dream jobs. However, the remaining $19 \%$ of the employed respondents would not recommend them to others. This means that majority of the respondents find the methods to be effective and helpful in aiding a job seeker to secure a job opening.

Table 4. Recommendation of Approach Used By Respondents for Others

\begin{tabular}{|c|c|c|}
\hline Category & Frequency & Percentage (\%) \\
\hline Yes & 107 & 81 \\
\hline No & 25 & 19 \\
\hline Total & 132 & 100 \\
\hline Source: Field Data (2013) & & \\
\hline
\end{tabular}




\subsection{Re-Use of Approach to Secure New Job}

In view of Table 5, (82\%) of the employed respondents revealed that they would re-use the approaches previously used in their job search to secure a new job when the need for that arises. The remaining, $18 \%$ of the employed respondents indicated they would not re-use the approaches previously used in securing their job if the need to secure a new job arises. This implies that the respondents feel a high rate of success was obtained when the above mentioned approaches was used and hence are very optimistic of similar or better resultsshould theneed arise for their re-use.

Table 5. Re-Use Of Approach by Respondents to Secure New Job

\begin{tabular}{|c|c|c|}
\hline Category & Frequency & Percentage (\%) \\
\hline Yes & 108 & 82 \\
\hline No & 24 & 18 \\
\hline Total & 132 & 100 \\
\hline Source: Field Data (2013) & & \\
\hline
\end{tabular}

\subsection{Difficulty Encountered}

When questioned about whether they had any difficulty looking for a job, the result in Table 6 showed that $44 \%$ of the employed respondents said they encountered some difficulties and the remaining $56 \%$ said they did not encounter any difficulty in their job search. Majority of the employed graduates indicated that they did not encounter any difficulty in their job search. This implies that, with the use of the various methods mentioned earlier, most of the graduate workers still encountered some difficulty in their job search. Even though, it may appear 1-6 months is a short period of time to secure a job, it entails follow ups, pleadings and a lot of waiting.

Table 6. Difficulty Encountered When Looking For a Job

\begin{tabular}{|c|c|c|}
\hline Category & Frequency & Percentage (\%) \\
\hline Yes & 58 & 44 \\
\hline No & 72 & 56 \\
\hline Total & 132 & 100 \\
\hline Source: Field Data (2013) & & \\
\hline
\end{tabular}

\subsection{Unemployed Graduates}

\subsubsection{Methods of Approach}

In reviewing the method of approach intended for use in job search by unemployed graduates, according to Table $7,23 \%$ of the unemployed respondents disclosed they intended to use application letters, $18 \%$ intended to use references from people, $21 \%$ intended to use personal contacts in their job search and $21 \%$ intended to use networking for their intended job search. In addition, 9\% intended to use internet website, $4 \%$ job fairs and $4 \%$ other methods such as the services of an employment agency. Majority of the unemployed respondents disclosed that they intended to use application letters in their job search followed closely by personal contacts and networking. Therefore in searching for jobs majority of unemployed graduates intend to use application letters and networking when searching for jobs. Like the employed graduates, it suggests job seekers have so much faith in the use of application letters, referees, contacts and networks. This mirrors the approaches used in Nigeria, United Kingdom and South Africa. What seem to be quite different in South Africa and Britain as compared to that in Ghana is that, in addition to the use of the above methods, graduates also resort to using recruitment agencies to secure a job. In Ghana the use of recruitment agencies is only slowly evolving.

Table 7. Method of Approach Intended For Use in Job Search

\begin{tabular}{|c|c|c|}
\hline Category & Frequency & Percentage (\%) \\
\hline Application Letter & 30 & 23 \\
\hline Reference from people & 23 & 18 \\
\hline Personal Contact & 27 & 21 \\
\hline Networking & 27 & 21 \\
\hline Internet websites & 11 & 4 \\
\hline Job fairs & 5 & 4 \\
\hline Others & 5 & 100 \\
\hline Total & 128 & \\
\hline Source: Field Data (2013) & & \\
\hline
\end{tabular}

\subsection{Reason for Method Used}

When asked why unemployed respondents would use the intended method in job search, Table 8 shows that $29 \%$ of the unemployed respondents said it is easier to use, $42 \%$ said because others have been successful at using and $2 \%$ said they had other reasons for using the intended method to secure a job and $27 \%$ indicated that, it is cost effective. Therefore, majority of the unemployed respondents disclosed that their intended use of the above methods of job search is because others have been successful at using such approaches: and thence they find it suitable to use them.

Table 8. Reason for Using This Method

\begin{tabular}{|c|c|c|}
\hline Category & Frequency & Percentage (\%) \\
\hline Easier to use & 37 & 29 \\
\hline Others have been successful at it & 54 & 42 \\
\hline Cost effective & 35 & 27 \\
\hline Others & 2 & 2 \\
\hline Total & 128 & 100 \\
\hline Source: Field Data (2013) & & \\
\hline
\end{tabular}

\subsection{Rating the Extent of Effectiveness in the Use of Job Search Methods}

Table 9, indicates that respondents consider the use of reference, personal contact, networking and internet website as the most effective methods of job search. Almost all the respondents 94\% expressed deep distrust in the use of job fairs to secure a job. Majority did not think the use of job fairs is effective at all. This implies that majority of the respondents did not believe that meeting with recruiters and company representatives at a career fair or career expo guarantees success in securing a job. Perhaps, they consider it as a useless exercise that only result in interacting with and obtaining contacts details of, and getting to know corporate recruiters without gaining any tangible job offer. 
Table 9. Rating Effectiveness in Securing a Job

\begin{tabular}{|c|c|c|c|c|c|c|}
\hline \multirow[b]{2}{*}{ Category } & \multicolumn{2}{|c|}{ Less Effective } & \multicolumn{2}{|c|}{ Effective } & \multicolumn{2}{|c|}{ Very Effective } \\
\hline & Frequency & $(\%)$ & Frequency & $(\%)$ & Frequency & $(\%)$ \\
\hline Application Letter & 43 & 33 & 66 & 52 & 19 & 15 \\
\hline Reference from people & 38 & 30 & 41 & 32 & 49 & 38 \\
\hline Personal Contact & 33 & 26 & 48 & 37 & 47 & 37 \\
\hline Networking & 49 & 38 & 44 & 34 & 35 & 28 \\
\hline Internet websites & 20 & 16 & 76 & 59 & 32 & 25 \\
\hline Job fairs & 120 & 94 & 8 & 6 & & \\
\hline Others & 112 & 88 & 16 & 12 & & \\
\hline Source: Field Data (2013) & & & & & & \\
\hline
\end{tabular}

\subsection{Length Anticipated}

Table 10 reveals that, respondents vary in their belief and conviction of the best approaches or methods to be used to secure a job. Majority of the respondents who have firm belief in the use of application letters think it takes 6months- 1year to secure a job using it, while the majority of those who believe in the use of referees think it will take 1-6months to secure a job using them. Similarly, majority of those who expressed confidence in the use of contacts, networks and internet website think it takes 6 months -1year to secure a job using them. The sum of the views expressed is that, majority of the respondents think it takes up to a year to secure a job in Ghana using application letters, referees, contacts, networks and internet websites.

\begin{tabular}{|c|c|c|c|c|c|c|}
\hline \multirow[b]{2}{*}{ Category } & \multicolumn{2}{|c|}{1 - 6 months } & \multicolumn{2}{|c|}{6 months -1 year } & \multicolumn{2}{|c|}{$1-5$ years } \\
\hline & Frequency & (\%) & Frequency & (\%) & Frequency & (\%) \\
\hline Application Letter & 38 & 30 & 72 & 56 & 18 & 14 \\
\hline Reference from people & 76 & 59 & 49 & 38 & 4 & 3 \\
\hline Personal Contact & 54 & 42 & 62 & 49 & 12 & 6 \\
\hline Networking & 37 & 29 & 71 & 55 & 20 & 16 \\
\hline Internet websites & 7 & 5 & 94 & 74 & 27 & 21 \\
\hline Job fairs & 2 & 2 & 17 & 13 & 109 & 85 \\
\hline Others & 64 & 50 & 64 & 50 & & \\
\hline Source: Field Data (2013) & & & & & & \\
\hline
\end{tabular}

\subsection{Difficulties Anticipated}

In examining the difficulties anticipated by the unemployed graduates in securing a job, Table 11 indicate that $34 \%$ of the respondents anticipated that, response from companies will not be quick, $12 \%$ of the respondents anticipated that application letters may get lost, 35\%of the respondents anticipated that competition may be faced from other applicants and 3\% have other views not expressed. The remaining $16 \%$ indicated that only few companies may respond. Majority of the respondents thus anticipate that competition may be faced from other applicants. This implies that majority of the respondents entertain the fear that the job market is at the moment very tight and therefore not easy to secure a job. This fear seems to be growing more and more with the downturn of the economy. Definitely, it is an unfortunate situation which graduates find themselves facing when looking for a job. The best career advice in this circumstance for the graduate unemployed is to increase the effort in the job search by remaining confident and persistent with their search. They should fear not.

Table 11. Difficulties Anticipated Encountering when Securing a Job

\begin{tabular}{|c|c|c|}
\hline Category & Frequency & Percentage (\%) \\
\hline $\begin{array}{c}\text { Response from companies will not } \\
\text { be quick }\end{array}$ & 44 & 34 \\
\hline Application letters may get lost & 15 & 12 \\
\hline $\begin{array}{c}\text { Competition may be faced from } \\
\text { applicants }\end{array}$ & 45 & 35 \\
\hline Only few companies may respond & 20 & 16 \\
\hline Others & 4 & 3 \\
\hline Total & 128 & 100 \\
\hline Source: Field Data (2013) & & \\
\hline
\end{tabular}

\section{Conclusions and Recommendations}

The study aimed at establishing the methods used by graduates in job search. A number of questions were posed for investigation. Towards this end, this chapter seeks to answer each of the questions posed for investigation.

The first research question has to do with which approaches are used by graduates in job search? Majority of the employed and unemployed graduates used internet websites, application letters, personal contacts, references by people and networking in their job search. This is in tandem with Hinshaw [9] who also admitted to the fact that job fairs, applying, networking and interviewing are some approaches used by graduates. What respondents seem not to use most often are job fairs and recruiting agencies. Their use is slowly evolving in Ghana and the researchers believe they will also become some of the preferred methods to be used in the future.

The second research question posed for answering was how effective are the approaches used in job search? In rating the effectiveness of the method of approaches intended for use and used in job search by employed and unemployed graduates, majority of them disclosed that the use of application letters, references from people, personal contacts, networking and internet websites, represent the effective methods used in the job search. On the other hand, ratings for the use of job fairs and other methods as discussed above was very low. This represents a contradictory view to westernized view as expressed by Fin [4] that job fairs are good places to meet many 
company representatives of all industries and sizes during a short period of time to transact on the prospect of receiving a job and/or actually receiving job offers.

The approaches used in searching for a job by the employed graduates produced good results. Majority of the respondents indicated that they were successful in the approaches used. Responses from companies where they sought for employment ranged from one month to a year. Majority of the employed respondents were able to obtain their preferred job using the above methods of job search. Respondents disclosed that they would re-use them again should the need arise and would recommend them to others.

Regarding the third research question on the challenges of searching for jobs using the above mentioned methods, the employed respondents indicated that they experienced some challenges in their job search and that they had to do with waiting for one month to a year to secure the job. The unemployed respondents anticipate a similar challenge in addition to the fear of having to compete for limited job opportunities. This is in agreement with Green [6] who voiced the concern that more people are in search for jobs than they are available. This is also consistent with Ross [18] view that making the move from higher education to employment can be difficult and complicated especially in tough economies like Ghana. The researchers agree with Ross that knowing how to go around this situation in finding the right work is a major skill. The researchers believe that this has to do with having the knowledge and wisdom of the job market, being confident and persistent at trying to secure exactly the kind of job in need of.

The study at evaluating the approaches used by graduates in job search in Ghana, employed and exploratory design approach by surveying both employed and unemployed graduates using a questionnaire. A total of 132 employed graduates and 128 unemployed graduates were reached for the study.

The findings of the study revealed that both the employed and unemployed graduates consider use of application letters, personal contacts, references and networking to be an effective means gaining job employment. Majority of the respondents indicated that, the response rate of companies to the use of the above mentioned methods of job search was very high and encouraging. Majority of the respondents indicated that they received responses from about five companies offering them a chance of dialogue about the possibility of handing them employment. Most of the employed graduates expressed their desire to recommend it and also to re-use them should the need to change job arise. The extent of their belief in the use of these methods of job search is that using them in job search can guarantee a favourable outcome of finding a job within one year.

The study recommends among others that organisations should ease the requirements used as criteria for qualification for employment so that more graduates can be offered work.

Also, it is suggested that graduates should be more confident and persistent in their job search, exploring more other job search options to secure themselves work. In addition, the researchers advise that HR experts and managers should build their recruitment and selection strategies around advert and the use of websites and social media.
The employed and unemployed graduates used internet websites, application letters, personal contacts, references by people and networking in their job search. It is to be assumed that the channels by which application letters were sent to prospective employers included applying through a website, hand delivering or mailing the application letter. In using the approach of networking the respondents may use/have used social networks such as LinkedIn and Facebook in their job search. Finally, with respect to the referencing approach to secure a job, respondents may have relied on friends and family recommending them to prospective employers.

The approaches used in searching for a job by the employed graduates produced good results. Majority of the respondents indicated that they were successful in the approach they used.

Responses from companies where they sought for employment ranged from one month to a year. Majority of the employed respondents were able to obtain their preferred job using application methods, networking, referees and contacts and disclosed that they would re-use them again should the need arise.

Majority of the employed and unemployed respondents in rating the effectiveness of the use of the above methods of job search indicated that they were effective to use, though they did not express confidence in their use of job fairs and other methods of job search.

The following recommendations are provided for unemployed graduates and students in their final year of school as well as to companies seeking to employ talented graduates. Job seekers are encouraged to employ the assistance of friends and family members who have the clout and links with corporate executives in order to boost their chances of securing a job. Also, it is recommended for the benefit of job seekers to engage themselves in voluntary work if they are unable to secure jobs immediately. Doing this will help them acquire employable skills. The experience which is gained will be beneficial in the search or hunt for a job in the future.

Corporate organisations are also encouraged to adopt a more friendly and flexible approach to the recruitment and selection of graduates. Recruitment and selection policies devised by organisations must take into account that most graduates are without practical skills and work experience and therefore should be given more opportunities of employment than the case. This will help them to acquire practical skills and work experience on the job.

Job seekers must be confident and persistent in the search for jobs. They must not entertain the fear that because they are in competition for the same jobs with others, they may lose one. Instead, they must explore more avenues of job search than the use of only a few methods of job search. They must cast their net wide and broad to increase their chances of finding their preferred jobs. A combination of the use of application letters, websites, referees and other less used methods like job fairs will be much more effective.

In addition, job seekers are advised to seek the help of consultants and experts to help them compose their application letters and CV's in a much more attractive and acceptable format. Composing application letters and CV's in a much more attractive and acceptable format helps the job seeker to increase his or her appeal and persuasiveness in convincing the employer to hire him or her. 
HR experts, HR consultants and practicing HR Managers are advised to craft their recruitment strategy around the use of advert; using the newspaper, website and social media as majority of respondents find the use of application, networking and websites to be effective in their job search. Also, employees could be used as referees to recommend competent staff at low cost to organisations.

\section{References}

[1] Blau, M. D. and Robins, P., K. (2000). Job search outcomes for the employed and unemployed. Journal of Political Economy, 98 (3), 637-655.

[2] Burda, M.C., and S. Profit (1996)." Matching Across Space: Evidence on Mobility in the Czech Republic," Labour Economics, 3: 255-278.

[3] Fin, A. and Morgan, S. (2006). Job search methods and results: Tracking the unemployed Monthly Labour Review; 115(12), 29-35.

[4] Fin, E. (2008). Job search methods: Internet versus traditional. Monthly Labour Review, October 2008, 3-11.

[5] Godbrah, C. (2006). Modelinghow search-matching technologies affect labour markets, talk given to IRPP and CERF conference on Creating Canada's Advantage in an Information Age, May 2006.

[6] Green, H. (2012). Five most effective job search methods, Upper Saddle River, NJ: Prentice-Hall.

[7] Hall, R. E. (1979). A Theory of Natural Unemployment Rate and theDuration of Employment, Journal of Monetary Economics, 5, 153-169.

[8] Haynes, J. 2009. Explaining BICS and CALP.[Online.] http://www.everythingesl.net/inservices/bics_calp_php Retrieved: 28/11/2009.

[9] Hinshaw, D. (2010). The dangers of online job hunting.Boston Metro, 13 September 2010, p. 16. References uncited studies.

[10] Huge, G. (2007). Search method use by unemployed youth. Journal of Labour Economics, 6 (1), 1-20.

[11] Holzer, H. (2000). "Racial Differences in Labor Market Outcomes Among Men.” In America Becoming: Racial Trends and their
Consequences, edited by N. Smelser et al. Washington, DC: National Academy Press.

[12] Kingston, E. (2004). Informal job search and black youth unemployment. American Economic Review, 77 (3), 446-452.

[13] McGregor, W. (2000).The secret of successful staff appraisal and counselling, Heinehan Professional Publishing, Oxford.

[14] Osberg, L. (2003). Fishing in different pools: Job search strategies and job-finding success in Canada in the early 1980s. Journal of Labour Economics, 11(2), 348-86.

[15] Pissarides, C. A. (2000). Equilibrium Unemployment Theory. Cambridge: MIT Press.

[16] Pissarides, C. A. (1979). Job matchings with state employment agencies and random search, Economic Journal, 89, 818-833.

[17] Richard, R., Robert, S., and Randall, W. (2005). SearchTheoretical Models of the Labour market: A Survey. Journal of Economic Literature. Vol. XLIII. Pp 959-988.

[18] Ross, P. K. (2004). "State Policies that Affect Working Families." Washington, DC: Urban Institute.

[19] Schmitt, J. and Wadsworth J. (2002). Unemployment benefits levels and search activity, Oxford Bulletin of Economics and Statistics, Vol. 55, Issue 1, p. 1-24.

[20] Seam, P. (2010). Offering a job: meritocracy and social networks. American Journal of Sociology, 106 (3), 763-816.

[21] Spokane, A. R. and Hawks, B.K. (1990). Annual review: practice and research in career counselling and development, 1989. The Career Development Quarterly 39, 98-128.

[22] Teichler, U. (2000). Graduate employment and work in selected European countries. European Journal of Education, 35 (2), 141156.

[23] Thompson, L. F., Braddy, P. W., \&Wuensch, K. L. (2008). Erecruitment and the benefits of organisational web appeal. Computers in Human Behaviour, 24(5), 2384-2398.

[24] Vilorio, D. (2011). Focused job seeking: A measured approach to looking for work. Occupational Outlook Quarterly. Retrieved 2012-10-22.

[25] Wanberg.C, R, Theresa, M.G., Zhaoli, S., and Sarah, S. (2005). Job-Search Persistence During Unemployment: A 10-Wave Longitudinal Study. Journal of Applied Psychology. Vol. 90, No.3, 411-430.

[26] Wielgosz, J.B. and Carpenter, S. (2004). The effectiveness of alternative methods of searching for jobs and finding them. American Journal of Economics, 12(6), 12-20. 